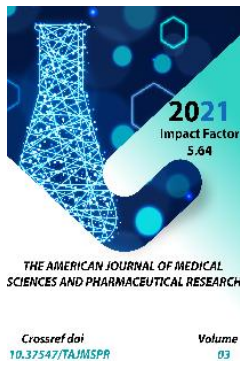

Copyright: Original content from this work may be used under the terms of the creative commons attributes 4.0 licence.

\section{Communication Of Quality Of Life Indicators, Functional Methods Of Research And Neuromarker BNDF In Patients With Diabetes Mellitus 2 With Diabetic Foot Syndrome}

\author{
Alimkhanov Olimkhon Omilkhonovich \\ Researcher, Department Of Diabetic Foot Of Purulent Complications Of Diabetes Mellitus, \\ Republican Specialized Scientific And Practical Medical Center Of Endocrinology Named After \\ Academician Y.Kh. Turakulova, 100125, Tashkent, Republic Of Uzbekistan \\ Kamalov Telman Tulyaganovich \\ Doctor Of Medical Sciences, Head Of The Department Of Diabetic Foot Of Purulent \\ Complications Of Diabetes Mellitus, Republican Specialized Scientific And Practical Medical \\ Center Of Endocrinology Named After Academician Y.Kh. Turakulova, 100125, Tashkent, Republic \\ Of Uzbekistan
}

\title{
ABSTRACT
}

The purpose of the study is to study the correlation rate of the quality of life, electroneuromyography, doppler and neuro markers BNDF in the blood in patients with a type 2 of type with diabetic foot syndrome.

Methods: The following 2 groups of patients were formed: 1 gr. - SDS patients, neuropathic form -37 patients, 2 gr. - SDS patients, neuroichmic form -35 patients, 3 gr. - Control group, these are 20 healthy persons of the appropriate age and gender.

Results: In all groups of patients, the quality of life is significantly different in the FSHC questionnaire compared with the control group $(p<0.05)$. In patients with a neuroecemic form of diabetic foot syndrome, a significant decrease was found $(p<0.05)$. All indicators of doppler song vessels of legs compared with patients with neuropathic shape.

Revealed significant correlations of FSHK and laboratory and instrumental indicators. A correlation connection with the duration of the disease, the duration of the disease, the levels of glycemia of an empty stomach, the level of the glycated haemoglobin, BNDF in the blood, the speed of blood flow in the femoral artery, in the lower leg, is discovered.

The definition of neuromuscular transmission showed that the patients of the 1st and 2nd groups have a weak reduction in muscle contraction involuntarily. This confirmed the impairment of neuromuscular transmission in both groups.

Conclusions: 1) A questionnaire to determine the quality indicators - FSHK is the most sensitive and informative to determine the quality of life in patients with type 2 diabetes mellitus with neuropathic and neuroecemic forms 
2) FSHP questionnaire can be used for dynamic assessment of type 2 diabetes patients with neuropathic and neuroecemic forms in outpatient clinical practice.

3) Revealed significant correlations of FSHK and laboratory and instrumental indicators. A correlation connection with the duration of the disease, the duration of the disease, the levels of glycemia on an empty stomach, the level of the glycated haemoglobin, BNDF in the blood, the speed of blood flow in the femoral artery, in the shin, M-answer when stimulating a tibial nerve.

\title{
KEYWORDS
}

Type 2 diabetes, diabetic foot syndrome

\author{
ABBREVIATION \\ DFS - diabetic foot syndrome; \\ QOL - the quality of life; \\ OCT - optical coherence tomography; \\ LEFS - Lower Extremity Functional Scale;
}

\section{INTRODUCTION}

Diabetes is a leading public health problem worldwide, as it is associated with various complications that significantly impair the quality of life (QOL) of patients. Moreover, one of the main complications of diabetes is diabetic foot syndrome (DFS), which leads to ulceration and amputation [1-5]. According to some researchers, DFS occurs in 30-80\% of patients with diabetes mellitus. Every fourth patient suffering from carbohydrate metabolism disorders is at risk of developing diabetic foot syndrome, and $615 \%$ of patients develop foot ulcers at some stage of diabetes mellitus $[8,20-27,16]$.

The development of pregangrene or an infectious process on the foot in patients with diabetes mellitus is the main cause of limb amputations in more than $50 \%$ of patients, and postoperative mortality is $15-20 \%$. [Levin M., Larson J., 2012].

In addition, from 6 to $30 \%$ of patients with diabetes mellitus after amputation of one limb during the first 3 years are amputated on the other limb, and after 5 years up to $51 \%$. [9, 19, 34].

The reasons for the high predisposition of patients with type II diabetes mellitus to the development of purulent-necrotic complications and gangrene of the limb consist in disrupting all types of metabolism, slowing down the processes of repair, disturbing microcirculation, developing immunological 
disorders and changing rheological blood values $[21.23,27]$.

A review by Chinese authors highlights the effect of fine fibres on cutaneous microcirculation and the need for prospective studies that can determine the course of microcirculation impairment over time Two important theories that have been put forward to explain observed abnormalities are the hemodynamic hypothesis and capillary snaking syndrome.

This article examines the development of microvascular dysfunction in the diabetic foot and discusses how this may be related to the pathogenesis of diabetic foot problems and ulcerations $[17,25]$.

In their study, the Australian authors applied a novel optical coherence tomography (OCT) technique during topical skin heating to assess the structure and function of microvessels in foot ulceration diabetics and healthy control [14]. This is evidence that it is possible to directly visualize and quantify microvessel function in people with diabetes, and distinguish the severity of microvascular disease between patients.

Another study describes the first evidence that optical coherent tomography provides direct imaging and comprehensive quantitative evaluation of cutaneous microvascular hemodynamics in response to reactive hyperemia. This imaging method will significantly improve the assessment of human skin microvessels in physiological and clinical settings [15].

The hopes placed in previous years for the correction of metabolic disorders, strict control of glycemia, as the main methods for the prevention of purulent-septic complications, in patients with type II diabetes mellitus after amputations of the limbs did not materialize (Tolstoy P.I., 1999; Savelyev B.C. et al., 2014).

Therefore, further search for ways to improve treatment outcomes and quality of life of this severe category of patients is justified) [29-33].

In recent years, works have appeared in the literature in which, within the framework of the pathogenesis of diabetic polyneuropathy, they pay close attention to growth factors that have the ability to simultaneously affect the vascular and metabolic components of pathogenesis. These include cerebral neurotrophic (BNDF) and vasculoendothelial growth factors. (Benjamin LE 2001, Sasi M. et al, 2017). According to modern studies, a certain pattern is revealed, manifested by an increase in the activation of these growth factors in the early stages of diabetic polyneuropathy, as a manifestation of compensatory mechanisms, and a significant decrease in their production during decompensation of the process, while the deficiency of neurotrophic factors becomes an independent pathogenetic link (Eyileten C. et al, 2017, Nakagawa T. et al, 2002, Leininger GM. Et al, 2004, Filimonova T.R., 2019).

All of the above emphasizes the relevance of this direction. In this regard, we formulated the following goal of the research work.

The study aimed to study the correlation between the quality of life indicators, electroneuromyography, Doppler sonography, and the BNDF neuro markers in the blood of patients with type 2 diabetes with diabetic foot syndrome.

\section{MATERIALS AND METHODS}

The following 2 groups of patients were formed: 1 gr. - patients with DFS, neuropathic form -37 patients, 2 gr. - patients with DFS, neuroischemic form -35 patients, 3 gr. - the control group is 20 healthy persons of the 
corresponding age and sex. All 72 patients underwent DFS surgery. Inclusion criteria: patients with type 2 diabetes mellitus, diabetic foot syndrome - neuropathic and neuroischemic forms. Exclusion criteria: patients with type 1 diabetes, patients with pathology of the cardiovascular system before the diagnosis of type 2 diabetes, who are on programmed hemodialysis, strokes, heart attacks, and oncological diseases.

In the study, patients were subjected to clinical and biochemical research methods (fasting glycemia, HbA1C, ALT, AST, bilirubin, urea, creatinine, PTI, BNDF in the blood, etc.), functional tests, as well as instrumental examination methods - ECG, electroneuromyography, Doppler vessels of the lower extremities, bacteriological analysis of wound discharge, determination of plantar pressure and the level of quality of life of patients (LEFS questionnaire), as well as statistical methods.

Lower Extremity Functional Scale (LEFS). LEFS consists of 20 statements, assessed on a fourpoint system from "no difficulties" (4 points) to "pronounced difficulties or impossibility of implementation" (o points). The calculation is carried out by summing the points for all points (the maximum number of points is 80 , the minimum is 0 ). The survey was carried out before and one and three months after the treatment. All patients were prescribed etiotropic (antibacterial) therapy and antioxidants (alpha-lipoic acid, 1 tablet 3 times a day).

The data obtained were processed using Microsoft Excel and STATISTICA_6 computer programs.

The arithmetic means (M), the standard deviation of the arithmetic mean, or the error of the arithmetic mean of all $n$ replicates $(m)$ were calculated. The significance of differences in the level between the groups was assessed by the value of the confidence interval and the Student's test ( $p)$. Differences were considered statistically significant at $p$ $<0.05$.

\section{RESULTS}

Table 1 shows the distribution of examined patients by sex and age. As can be seen from Table 1, patients in the age category from 45 to 59 years old prevailed both among men and women - 47/25 cases, respectively. Table 2 shows the duration of observations by groups. As can be seen from Table 2, the predominant number of patients were observed for up to 1 year - 9/10 (26\%) patients, and the smallest number - up to 5 years - $2 / 2$ patients, respectively (6\%).

Table 1. Distribution of patients by sex and age (WHO, 2017)

\begin{tabular}{ccc}
\hline Age, years & Number of men & Number of women \\
\hline 18-44 (young age) & $11(23,4 \%)$ & $7(28 \%)$ \\
$45-59$ (middle age) & $15(31,9 \%)$ & $4(16 \%)$ \\
$60-74$ (advanced age) & $18(38,3 \%)$ & $11(44 \%)$ \\
75 and older (old age) & $3(6,4 \%)$ & $3(12 \%)$ \\
Total: $\mathrm{n}=72$ & $47(65,3 \%)$ & $25(34,7 \%)$ \\
\hline
\end{tabular}


Table 2. Duration of observations by groups. (abs. numbers and \%)).

Duration of observations, years

\begin{tabular}{ccc}
\hline Up to 1 year, $\mathrm{n}=17$ & $1 \mathrm{gr}, \mathrm{n}=37$ & $2 \mathrm{gr}, \mathrm{n}=35$ \\
From 1 to 2 years, $\mathrm{n}=10$ & $9(28 \%)$ & $10(28,6 \%)$ \\
2 years, $\mathrm{n}=9$ & $6(16 \%)$ & $8(22,9 \%)$ \\
3 years, $\mathrm{n}=7$ & $11(20 \%)$ & $6(17,1 \%)$ \\
4 years, $\mathrm{n}=5$ & $4(8 \%)$ & $5(14,3 \%)$ \\
5 years, $\mathrm{n}=2$ & $5(12 \%)$ & $3(8,6 \%)$ \\
\hline
\end{tabular}
Groups of patients, abs.

Note: in the column \% - the percentage of patients of the total number of patients in the group is given

During the examination, the patients presented various complaints indicating the presence of DFS. In both groups of patients, the most common complaints were paresthesias - 44 ( $88 \%$ of the total number of patients in 2 groups), fatigue of the legs when walking - 40 (80\%), cold feet - $37(74 \%)$, pain in the lower extremities - 32 (64\%), discolouration of the extremities - 29 (58\%), that is, these complaints are most typical for chronic vascular insufficiency in the lower extremities. These complaints are presented in Table 3 by the group.

Table 3. Characteristics of patient complaints by groups. (abs. numbers and\%)).

\begin{tabular}{|c|c|c|}
\hline \multirow{2}{*}{ Complaints } & \multicolumn{2}{|c|}{ Groups of patients, abs. } \\
\cline { 2 - 3 } & $1 \mathrm{gr}, \mathrm{n}=37$ & $2 \mathrm{gr}, \mathrm{n}=35$ \\
\hline lower limb pain & $27(73 \%)$ & $35(100 \%)$ \\
\hline paresthesia & $19(51,3 \%)$ & $35(100 \%)$ \\
\hline leg fatigue when walking & $15(40,5 \%)$ & $35(100 \%)$ \\
\hline changing limb colour & $21(56,7 \%)$ & $35(100 \%)$ \\
\hline cooling of feet & $37(100 \%)$ & $35(100 \%)$ \\
\hline
\end{tabular}

Note: in the column\% - the percentage of patients from the total number of patients in the group is given.

The next stage of the work was the study of the quality of life of patients using the functional scale of the lower extremities
(LEFS). Table 4 shows the characteristics of the results obtained in 72 patients through these studies. 
Table 4. The results of the functional scale of the lower extremities for assessing the quality of life in groups

\begin{tabular}{|c|c|c|c|}
\hline \multirow{2}{*}{ Indicators } & \multicolumn{3}{|c|}{ group } \\
\hline & 1 gr. $n=37$ & 2 gr. $n=35$ & Control. $\mathrm{n}=20$ \\
\hline $\begin{array}{l}\text { 1. Perform regular work at home or } \\
\text { during training }\end{array}$ & $3 \pm 0,3^{*}$ & $1 \pm 0,5^{*}$ & $4 \pm 0,2$ \\
\hline 2. Engage in your usual hobby or sports & $2 \pm 0,2^{*}$ & $1 \pm 1,2^{*}$ & $4 \pm 0,3$ \\
\hline 3. Get in or out of the bath & $2 \pm 0,6 *$ & $1 \pm 0,5^{*}$ & $4 \pm 0,2$ \\
\hline 4. Move from room to room & $3 \pm 0,7^{*}$ & $1 \pm 0,9^{*}$ & $4 \pm 0,1$ \\
\hline 5. Wear socks and shoes & $3 \pm 0,3^{*}$ & $1 \pm 0,5^{*}$ & $4 \pm 0,2$ \\
\hline 6. Squat on the crusts & $2 \pm 0,4^{*}$ & $1 \pm 0,8^{*}$ & $4 \pm 0,2$ \\
\hline $\begin{array}{l}\text { 7. Lift items from the floor, such as food } \\
\text { bags }\end{array}$ & $2 \pm 0,6 *$ & $1 \pm 0,7^{*}$ & $4 \pm 0,3$ \\
\hline 8. Perform Heavy Physical Housework & $3 \pm 0,8^{*}$ & $1 \pm 0,9^{*}$ & $4 \pm 0,2$ \\
\hline 9. Do Hard Physical Housework & $3 \pm 0,3^{*}$ & $1 \pm 0,7^{*}$ & $4 \pm 0,1$ \\
\hline 10. Come in or out of the car & $2 \pm 0,2^{*}$ & $1 \pm 0,6^{*}$ & $4 \pm 0,5$ \\
\hline 11. Walk up to $250 \mathrm{~m}$ & $2 \pm 0,9^{*}$ & $1 \pm 0,7^{*}$ & $4 \pm 0,7$ \\
\hline 12. Walk up to $1.5 \mathrm{~km}$ & $3 \pm 0,7^{*}$ & $1 \pm 0,9^{*}$ & $4 \pm 0,4$ \\
\hline $\begin{array}{l}\text { 13. Go down or climb stairs for one span } \\
\text { (10 steps) }\end{array}$ & $3 \pm 0,3^{*}$ & $1 \pm 0,5^{*}$ & $4 \pm 0,9$ \\
\hline 14. Stand for 1 hour & $2 \pm 0,5^{*}$ & $1 \pm 0,8^{*}$ & $4 \pm 0,2$ \\
\hline 15. Sit for 1 hour & $2 \pm 0,6^{*}$ & $1 \pm 0,7^{*}$ & $4 \pm 0,2$ \\
\hline 16. Run on a flat surface & $3 \pm 0,7^{*}$ & $1 \pm 0,9^{*}$ & $4 \pm 0,2$ \\
\hline 17. Run through rough terrain & $3 \pm 0,7^{*}$ & $1 \pm 0,5^{*}$ & $4 \pm 0,3$ \\
\hline 18. Turn abruptly in the running process & $2 \pm 0,2^{*}$ & $1 \pm 0,2^{*}$ & $4 \pm 0,5$ \\
\hline 19. To jump up & $2 \pm 0,9 *$ & $1 \pm 0,7^{*}$ & $4 \pm 0,7$ \\
\hline 20. Flip in bed & $3 \pm 0,7^{*}$ & $1 \pm 0,9^{*}$ & $4 \pm 0,8$ \\
\hline
\end{tabular}

Note: * reliability of differences with control, where * $-p<0.05$

As can be seen from Table 4, in all groups of patients, the indicators of the quality of life according to the LEFS questionnaire significantly differ in comparison with the control group $(p<0.05)$. Thus, the study of the quality of life of patients using LEFS in 2 groups of patients with type 2 diabetes mellitus with DFS revealed pronounced changes in the above indicators of quality of life in group 2 of patients. These statistics indicate the need for further research in the dynamics of patient follow-up. The obtained results also confirm the literature data that patients with type 2 diabetes mellitus with neuroischemic form DFS have a low quality of life indicators. Next, we evaluated the sensitivity of the LEFS questionnaire in the dynamics of research. The results of this analysis are presented in Table 5 .

Table 5. Assessment of the sensitivity of the LEFS questionnaire by groups 


\begin{tabular}{|c|c|c|c|c|c|c|c|}
\hline \multicolumn{2}{|c|}{ questionnaire } & $\begin{array}{c}\text { Initial } \\
\text { testing } \\
\mathrm{M} \pm \mathrm{m}\end{array}$ & $\begin{array}{c}\text { After } 1 \\
\text { month, } \\
\mathrm{M} \pm \mathrm{m}\end{array}$ & $\begin{array}{l}\text { After } 3 \\
\text { months, } \\
M \pm m\end{array}$ & $\begin{array}{c}\mathrm{t}- \\
\text { test }\end{array}$ & $\mathrm{p}$ & $\begin{array}{l}\text { Effect } \\
\text { size, } \\
M \pm \\
m\end{array}$ \\
\hline LEFS & $\begin{array}{c}40,1 \pm 4 \\
12\end{array}$ & $57,7 \pm 3,6$ & $78,2 \pm 2,7$ & $\begin{array}{c}- \\
6,87\end{array}$ & 0,0001 & & $\begin{array}{c}- \\
, 87 \pm 2,3\end{array}$ \\
\hline
\end{tabular}

Sensitivity is a property of the method that allows you to record changes in the studied parameters over time. Therefore, the assessment of the questionnaires was carried out in dynamics against the background and after outpatient treatment. The LEFS questionnaire showed sufficient sensitivity in patients with DFS. The percentage of improvement in dynamics according to the LEFS questionnaire showed $86.7 \%$. Next, we performed an analysis of Doppler studies of the vessels of the lower extremities in both groups of patients. The results are shown in Table 6.

Comparison of Doppler sonography of the vessels of the lower extremities in 2 groups of patients showed that in patients of group 1, the blood flow in the lower extremities was turbulent, and in group 2, it was collateral.

Average indicators of blood flow velocity in patients of group 1 in the femoral artery were $78.1 \pm 3.3$ (normal $100 \mathrm{~cm} / \mathrm{sec}$ ) and in the lower leg $39.1 \pm 4.6$ (normal $50 \mathrm{~cm} / \mathrm{sec}$ ). The

Table 6. Results of Doppler ultrasound of the vessels of the lower extremities by groups. (abs. numbers and \%)).

\begin{tabular}{|c|c|c|c|}
\hline \multirow{2}{*}{ Indicators } & \multicolumn{3}{|c|}{ Groups of patients, abs. } \\
\cline { 2 - 4 } & $\begin{array}{c}1 \mathrm{gr} \\
\mathrm{n}=37\end{array}$ & $\begin{array}{c}2 \mathrm{gr} \\
\mathrm{n}=35\end{array}$ & $\begin{array}{c}\text { control } \\
\mathrm{n}=20\end{array}$ \\
\hline $\begin{array}{c}\text { blood flow velocity in the femoral } \\
\text { artery, } \mathrm{cm} / \mathrm{sec}\end{array}$ & $78,1 \pm 3,3$ & $34,7 \pm 6,2$ & $100 \pm 16,2$ \\
\hline blood flow velocity in the leg, $\mathrm{cm} / \mathrm{sec}$ & $39,1 \pm 4,6$ & $22,3 \pm 3,2^{*}$ & $50 \pm 9,8$ \\
\hline Femoral artery resistance index, $\mathrm{m} / \mathrm{s}$ & $0,6 \pm 0,08$ & $0,2 \pm 0,06^{*}$ & $1,0 \pm 0,9$ \\
\hline Ripple index in the tibial artery, $\mathrm{m} / \mathrm{s}$ & $1,0 \pm 0,7$ & $0,4 \pm 0,05^{*}$ & $1,8 \pm 0,6$ \\
\hline
\end{tabular}

Note: * - reliability of differences with control, where * $-p<0.05$ resistance index in the femoral artery was in the range of $0.6 \pm 0.08 \mathrm{~m} / \mathrm{s}$ (normally exceeds 1 $\mathrm{m} / \mathrm{s})$. The pulsation index in the tibial artery was within $1.0 \pm 0.7 \mathrm{~m} / \mathrm{s}$ (normally more than 1.8 $\mathrm{m} / \mathrm{s})$.

The average blood flow velocity in group 2 patients in the femoral artery was $34.7 \pm 6.2$ (normal $100 \mathrm{~cm} / \mathrm{sec}$ ), and $22.3 \pm 3.2$ in the lower leg (normal $50 \mathrm{~cm} / \mathrm{sec}$ ). The resistance index in the femoral artery was within $0.2 \pm 0.06 \mathrm{~m} / \mathrm{s}$. The pulsation index in the tibial artery was in the range of $0.4 \pm 0.05 \mathrm{~m} / \mathrm{s}$ (normally more than $1.8 \mathrm{~m} / \mathrm{s}$ ).

Thus, in patients with the neuroischemic form of diabetic foot syndrome, a significant decrease $(p<0.05)$ was found in all Doppler sonography parameters of the leg vessels compared with patients with the neuropathic form. 
The next stage of our research was the study of electroneuromyographic studies.

The results are shown in Table 7. Comparison of electroneuromyography indices showed that in the 1st group of patients the muscle response was better than in patients from the 2nd group. Determination of neuromuscular transmission showed that patients of the 1st and 2nd groups have a weak contraction of muscle contraction involuntarily. This confirmed the violation of neuromuscular transmission in both groups. The signal speed in the 1st group of patients was slightly reduced in comparison with the control, especially in the 2nd group. The number of muscle sites that should be responsible for irritation (M-response) was reduced several times, more in group 2. It was found that each stage of diabetic polyneuropathy is characterized by its own spectrum of changes in the provision of neuroplasticity mechanisms. So, according to the data of Filimonova T.A. (2019), at the early stage of diabetic polyneuropathy, there is a significant increase in the content of the brain neurotrophic factor.

Table 7. Results of electroneuromyographic studies in groups. (abs. numbers and\%)).

\begin{tabular}{|c|c|c|c|}
\hline \multirow[b]{2}{*}{ Indicators } & \multicolumn{3}{|c|}{ Groups of patients, abs. } \\
\hline & $\begin{array}{c}1 \mathrm{gr} \\
\mathrm{n}=37\end{array}$ & $\begin{array}{c}2 \text { gr, } \\
\mathrm{n}=35\end{array}$ & $\begin{array}{c}\text { Control, } \\
\mathrm{n}=20\end{array}$ \\
\hline \multicolumn{4}{|c|}{$\begin{array}{l}\text { Indicators } \mathrm{M} \text { - the response of the short extensor of the toes during stimulation of the } \\
\text { peroneal nerve. }\end{array}$} \\
\hline Latency, ms & $4,2 \pm 0,25$ & $4,03 \pm 0,68$ & $3,27 \pm 0,23$ \\
\hline Amplitude, mV & $4,15 \pm 1,02$ & $3,42 \pm 2,39$ & $5,7 \pm 2,9$ \\
\hline SPE, $\mathrm{m} / \mathrm{s}$ & $43,6 \pm 5,21$ & $42,05 \pm 3,52$ & $46,7 \pm 3,4$ \\
\hline \multicolumn{4}{|c|}{ ENMG indicators of the fibular nerve (sensitive portion). } \\
\hline Latency, ms & $2,12 \pm 0,61$ & $1,52 \pm 0,44$ & $2,24 \pm 0,49$ \\
\hline Amplitude, $\mathrm{mV}$ & $13,34 \pm 3,63$ & $7,25 \pm 5,19$ & $13,9 \pm 4,0$ \\
\hline $\mathrm{SPE}, \mathrm{m} / \mathrm{s}$ & $41,2 \pm 4,12$ & $40,36 \pm 6,75$ & $42,3 \pm 3,4$ \\
\hline \multicolumn{4}{|c|}{$\begin{array}{l}\text { M - response indicators when stimulating the tibial nerve and recording the induced } \\
\text { potential from the muscle. }\end{array}$} \\
\hline Latency, ms & $3,65 \pm 0,48$ & $4,12 \pm 0,36$ & $4,3 \pm 0,5$ \\
\hline Amplitude, mV & $7,16 \pm 3,73$ & $8,23 \pm 3,76$ & $8,8 \pm 1,9$ \\
\hline SPE, $\mathrm{m} / \mathrm{s}$ & $42,5 \pm 3,98$ & $43,6 \pm 3,00$ & $48,5 \pm 3,6$ \\
\hline \multicolumn{4}{|c|}{ ENMG tibial nerve indicators (sensitive portion) } \\
\hline Latency, ms & $2,29 \pm 0,34$ & $2,28 \pm 0,35$ & $3,1 \pm 0,5$ \\
\hline Amplitude, $\mathrm{mV}$ & $8,32 \pm 2,52$ & $10,43 \pm 6,84$ & $10,32 \pm 3,9$ \\
\hline SPE, $\mathrm{m} / \mathrm{s}$ & $43,07 \pm 3,33$ & $42,09 \pm 6,19$ & $43,8 \pm 6,3$ \\
\hline
\end{tabular}

Note: SPE is the speed of propagation of excitation

As shown in Table 8, serum BDNF levels in groups 1 and 2 of DFS patients significantly exceed those in the control group. 
Table 8. Table 8. Comparative analysis of the content of brain neurotrophic growth factor (BNDF) in the serum of patients in the compared groups

\begin{tabular}{ccccc}
\hline Indicator & Monitoring Group & 1st group & 2nd group & p-value \\
BDNF, ng/ml & $1,07 \pm 0,64$ & $2,12 \pm 0,32$ & $4,74 \pm 1,09$ & 0,001 \\
\hline
\end{tabular}

Table 9. Correlation (r) of LEFS values with laboratory and instrumental indicators

\begin{tabular}{|c|c|c|c|c|c|c|c|}
\hline 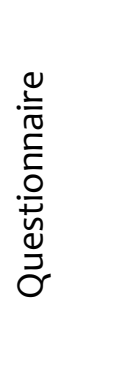 & 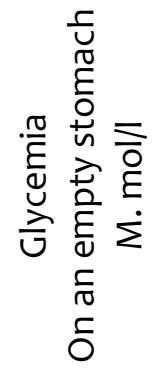 & 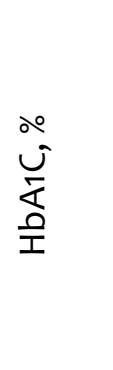 & 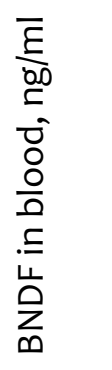 & 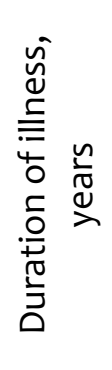 & 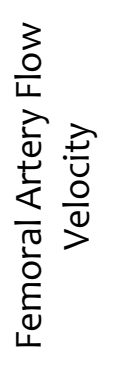 & 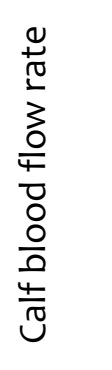 & 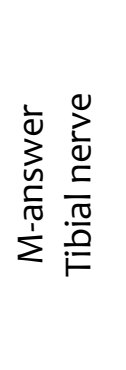 \\
\hline LEFS & 0,35 & 0,38 & 0,64 & 0,59 & 0,54 & 0,45 & 0,48 \\
\hline
\end{tabular}

As can be seen from Table 8, significant correlations between LEFS and laboratoryinstrumental indicators were revealed. A correlation was found with the duration of the disease, the duration of the disease, the levels of fasting glycemia, the level of glycated haemoglobin, BNDF in the blood, the blood flow velocity in the femoral artery, in the lower leg, as well as the M-response upon stimulation of the tibial nerve. All of the above data indicate the need for timely adequate conservative therapy of chronic wound defects of the lower extremities in patients with diabetes mellitus, the development of measures to prevent their recurrence and the organization of long-term follow-up of patients with a high risk of developing this complication of diabetes.

\section{CONCLUSION}

1) Questionnaire for determining the quality of life indicators - LEFS is the most sensitive and informative for determining the quality of life in patients with type 2 diabetes mellitus with neuropathic and neuroischemic forms.

2) The LEFS questionnaire can be used for the dynamic assessment of patients with type 2 diabetes mellitus with neuropathic and neuroischemic forms in outpatient clinical practice.

3) Revealed significant correlations between LEFS and laboratory and instrumental indicators. A correlation was found with the duration of the disease, the duration of the disease, the levels of fasting glycemia, the level of glycated haemoglobin, BNDF in the blood, the blood flow velocity in the 
femoral artery, in the lower leg, the $M$ response upon stimulation of the tibial nerve.

\section{REFERENCES}

1. Beloedova, M.V. (2005). Improving the quality of life of gerontological patients with distal diabetic macroangiopathy by reducing the level of amputation (Doctoral dissertation, Moscow State University of Medicine and Dentistry).

2. Burkovsky, G.V., Kotsyubinsky, A.P., Levchenko, E.V., \& Lomachenkov, A.S. (1995). Creation of the Russian version of the World Health Organization tool for measuring the quality of life. Problems of optimization of human lifestyle and health, 27-28.

3. Wasserman, L.I., \& Trifonov, E.A. (2006). Methodology for studying the quality of life in the context of psychosomatic and somatopsychic relationships. VM Bekhterev Review of Psychiatry and Medical Psychology, (4), 12-15.

4. Wasserman, L.I., Gromov, S.A., Mikhailov, V.A., Lynnik, S.D., \& Flerova, I.L. (2001). Rehabilitation and quality of life concepts: continuity and differences in modern approaches. In Psychosocial Rehabilitation and Quality of Life (pp. 103115).

5. Kulaga, V.A. (2010). Results of lower limb amputations in critical ischemia (Doctoral dissertation, Military Medical Academy). P.137.
6. Malakhov, Yu.S. (2009). Surgical methods of treatment of ischemia of the lower extremities of the IV degree (Doctoral dissertation, speciality 14.00. $27-$ surgery).

7. Mikhailov, V.G. (2005). Complex treatment of patients with ischemic diabetic foot complicated by gangrene (Doctoral dissertation, Moscow State University of Medicine and Dentistry). P.91.

8. Novik, A.A., \& Ionova, T.I. (2007). Guidelines for the study of quality of life in medicine. 2nd edition/Under. ed. acad. RAMS Yul Shevchenko. Moscow: ZAO OLMA Media Group, 2007.320 p. Novik AA, Ionova TI Rukovodstvo po issledovaniyu kachestva zhizni $v$ meditsine. 2-e izdaniye/Pod. red. Akad. RAMN Yu. L. Shevchenko. $M$ :: ZAO "OLMA Media Grupp", 2007.320 s.

9. Golovina, G.M., \& Savchenko, T.N. (2006). Subjective quality of life: approaches, assessment methods, applied research. Moscow: Publishing house of the Institute of Psychology RAS, 170.

10. Suprun, K.S. (2009). Influence of microcirculation disorders on the surgical tactics of treating diabetic foot syndrome. P.118.

11. Smirnova, L.M. (2010). Methodology and unified technology for assessing the functional effectiveness of prosthetics and orthotics in patients with lower limb pathology. SPb. P. 338.

12. Selezneva, E.V. (2004). Diagnostics and treatment of diabetic foot syndrome at 
the prehospital stage (Doctoral dissertation, speciality 14.00. 27 surgery). P. 133.

13. Triandafilov, K.G. (2009). Surgical tactics and methods of surgical treatment of complicated diabetic foot syndrome (Doctoral dissertation, speciality 14.00. 27 - surgery). P. 162.

14. Argarini, R., McLaughlin, R. A., Joseph, S. Z., Naylor, L. H., Carter, H. H., Yeap, B. B., ... \& Green, D. J. (2020). Optical coherence tomography: a novel imaging approach to visualize and quantify cutaneous microvascular structure and function in patients with diabetes. BMJ Open Diabetes Research and Care, 8(1), e001479. DOI: 10.1136/bmjdrc-2020-001479

15. Argarini, R., McLaughlin, R. A., Joseph, S. Z., Naylor, L. H., Carter, H. H., Haynes, A., ... \& Green, D. J. (2020). Visualizing and quantifying cutaneous microvascular reactivity in humans by use of optical coherence tomography: impaired dilator function in diabetes. American Journal of Physiology-Endocrinology and Metabolism, 319(5), E923-E931. DOI: 10.1152/ajpendo.00233.2020. Epub 2020 Sep 21.

16. Bradley, C. (2001). Importance of differentiating health status from the quality of life. The Lancet, 357(9249), pp.78.

17. Chao, C. Y., \& Cheing, G. L. (2009). Microvascular dysfunction in diabetic foot disease and ulceration. Diabetes/metabolism research and reviews, 25(7), 604-614. DOI: 10.1002/dmrr.1004.
18. Guyatt, G. H., Bombardier, C., \& Tugwell, P. X. (1986). Measuring disease-specific quality of life in clinical trials. CMAJ: Canadian Medical Association Journal, 134(8), P.889.

19. Garratt, A. M., Ruta, D. A., Abdalla, M. I., Buckingham, J. K., \& Russell, I. T. (1993). The SF36 health survey questionnaire: an outcome measure suitable for routine use within the NHS?. British Medical Journal, 306(6890), 1440-1444.

20. Hörnquist, J. O. (1982). The concept of quality of life. Scandinavian journal of social medicine, 10(2), pp. 57-61.

21. Hunt, S. M., McEwen, J., \& McKenna, S.P. (1985). Measuring health status: a new tool for clinicians and epidemiologists. The Journal of the Royal College of General Practitioners, 35(273), pp.185-188.

22. Jenkinson, C., Fitzpatrick, R., \& Argyle, M. (1988). The Nottingham Health Profile: an analysis of its sensitivity in differentiating illness groups. Social Science \& Medicine, 27(12), pp.1411-1414.

23. Moons, P., Marquet, K., Budts, W., \& De Geest, S. (2004). Validity, reliability and responsiveness of the" Schedule for the Evaluation of Individual Quality of LifeDirect Weighting"(SEIQoL-DW) in congenital heart disease. Health and quality of life outcomes, 2(1), pp.1-8.

24. Czajkowski, S. M., \& McSweeny, A. J. (1996). The role of psychosocial factors in chronic obstructive pulmonary disease. 
Physical Medicine and Rehabilitation Clinics, 7(2), pp.341-352.

25. Neroev, V. V., Kiseleva, T. N., Okhotsimskaya, T. D., Fadeeva, V. A., \& Ramasanova, K. A. (2018). Impact of antiangiogenic therapy on ocular blood flow and microcirculation in diabetic macular oedema. Vestnik oftalmologii, 134(4), 3-10. DOI: 10.17116/oftalma20181340413.

26. Polonsky, W. H. (2000). Understanding and assessing the diabetes-specific quality of life. Diabetes Spectrum, 13(1), P.36.

27. Rubin, R. R. (2000). Diabetes and quality of life. Diabetes Spectrum, 13(1), P.21.

28. Rosenthal, M. J., Fajardo, M., Gilmore, S., Morley, J. E., \& Naliboff, B. D. (1998). Hospitalization and mortality of diabetes in older adults: a 3-year prospective study. Diabetes care, 21(2), pp.231-235.

29. Singh, H., \& Bradley, C. (2006). Quality of life in diabetes. International Journal of Diabetes in Developing Countries, 26(1).

30. Snoek, F. J. (2000). Quality of life: a closer look at measuring patients' well-being. Diabetes Spectrum, 13(1), pp.24-28.

31. Surtees, P. G., Wainwright, N. W., Khaw, K. T., \& Day, N. E. (2003). Functional health status, chronic medical conditions and disorders of mood. The British Journal of Psychiatry, 183(4), pp.299-303.

32. Vileikyte, L., Peyrot, M., Bundy, C., Rubin, R. R., Leventhal, H., Mora, P., ... \& Boulton,
A. J. (2003). The development and validation of a neuropathy-and foot ulcerspecific quality of life instrument. Diabetes care, 26(9), pp.2549-2555.

33. Wenger, N. K., Mattson, M. E., Furberg, C. D., \& Elinson, J. (1984). Assessment of quality of life in clinical trials of cardiovascular therapies. American Journal of Cardiology, 54(7), pp.908-913.

34. Ware J.E., Kosinski M., Gandek B. (1993, 2000)/ SF-36 Health Survey: Manual and Interpretation Guide. Quality Metric Incorporated, Lincoln, RI. - 2000.

35. Wasserman, L. I., \& Trifonova, E. A. (2006). Diabetes mellitus as a model of psychosomatic and somatopsychic interrelationships. The Spanish journal of psychology, 9(1), P.75. 